congested, and after death occasionally patches of hepatised lung are discovered, while the greater portion of lung tissue is destroyed by œdema. The name "congestive catarrh" has been given to this state. The pneumonia of the eruptive fevers, scarlatina, small-pox, etc., is of this kind, and appears generally to be an extension of disease from the mucous linings of the bronchial tubes: though isolated patches of hepatised lung are found, the general condition is that of congestion and œdema.

It has been a matter of greater dispute whether malaria or the poison of fever can produce pneumonia. From well directed observations, it appears to be satisfactorily settled. Dr. Morehead, in a report on pneumonia, as observed in the Hospital at Bombay, has noticed the occurrence of this disease, complicating intermittent and remittent fevers. He says, "From five to eight grains of quinine, with from one-tenth to one-fourth grain of tartar emetic, given at intervals of two or three hours for five or six doses, will in general suftice to check, and then stop, the febrile recurrences. When this effect on the febrile symptoms has been produced, it will generally be found that improvement in pneumonia will at once commence; and, in a large majority of cases, if the recurrence of the febrile state be prevented for some days, the in flammation will be speedily removed." He adds, "I am not acquainted with anything more striking and satisfactory, in the whole range of rational therapeutics, than the progressive but speedy restoration of an hepatised lung, coexisting with fever of remittent type, when the exacerbations have been controlled by the adequate use of quinine."

To an altered state of blood is to be attributed no small share in the development of pneumonia. That the blood undergoes sume important change, both from the effects of the fever poison as well as from the course of the disease, is evident from the careful analyses of chemists-Andral, Simon, and others. We find certain elements gradually wasting, while others are in proportion increasing; and that, as certain products are abundant, so have we a tendency to inflammatory conditions. We know full well the disposition to the accession of pneumonia when fever is declining. Now is it not probable that, in our over zeal to save our patients from sinking, by affording them a highly nutritious and stimulating diet, while the excreting organs are scarcely able to perform their functions, we may increase too suddenly those products which, together with the tendency to congestion from debility, give rise to pneumonia? In almost every case, when this disease has arisen, we find the urine loaded with those deposits which prove to us that the blood is overcharged with nitrogenised matter. Of this I am sure, that since I have been very guarded in the administration of stimulants, and the richer kinds of animal food, I have seen much less of pneumonic complica tions in fever. Some very admirable remarks on the treatment of fever will be found in a report by Dr. Wilks, in Guy's Hos pital Reports, vol. i, 1855, and in a review of that report published in Ranking's Half-Yearly Abstract, January to June, 1856.

I have hitherto spoken of the absence of symptoms which prevent our readily recognising pneumonia. I should not forget to mention the presence of other diseases, which are attended with symptoms characteristic of inflammation of the lungs; the chief of which are, congestions from old standing disease of the internal organs, heart, liver, kidneys, etc.

An old gentleman, seized with pain in his left side, fever, heat of skin, dyspnœa, and cough, came under my observation. His chest was carefully examined; there was small crepitation over the back part of both lungs, more especially the left, and dulness on percussion, both anteriorly and posteriorly. His cough was troublesome, and he expectorated a quantity of rusty coloured and bloody sputa; indeed, there were apparently very evident signs of pneumonia. Mercury was given in small doses; the gums became affected, counterirritants were applied over the chest and back, perfect rest was enjoined, and the patient was supposed to be progressing favourably. $\mathrm{He}$ died suddenly after some slight but unusual exertion, and during the progress of the disease. An examination of the chest was allowed, and to my astonishment, there was not and had not been pneumonia at all. The heart was flabby, and so soft that I could readily poke my fingers through any part of it The lungs were congested and œdematous, the liver large and fatty, and the kidneys, like all the other organs, much con gested. Death no doubt ensued from over exertion, the fatt degenerating heart being unable to cope with the accelerated circulation.

I have seen similar pneumonic symptoms exist when, I 169 believe, the real seat of disease has been the capillary system generally. I have not had many opportunities of witnessing this condition; the prominent symptoms were such as would lead one to suspect heart disease; but the heart's sounds and actions were good; there existed congestions of the internal organs, and a blue congested state of skin. I could only account for the disease by supposing that the obstruction to the circulation, instead of being in the aorta, or about the valves, was eccentric and in the capillaries generally.

\section{CLINICAL OBSERVATIONS ON THE SPECIAL APPLICATION OF LIQUOR PEPSINIAE IN CERTAIN DISEASES.}

By David Nelson, M.D.Edin., formerly Physician to the Quèen's Hospital, and Professor of Clinical Medicine, Birmingham. [Concluded from page 133.]

C. DYSPEPSIA, WITH ABDOMINAL TUMOURS, ETC.

Case I. Miss A. T., from the neighbourhood of Temple, aged about 32 , complained of painful indigestion and vomiting, and of constipation alternating with irksome diarrhœa, the latter usually consisting of frequent, teazing, thin stools, in very small quantity, but sometimes relapsing into frequent attempts with only the passage of small scybala. She had taken stomachic mixtures, and aperient medicines; but the latter had usually caused great uneasiness, with very little result in the way of evacuation, and she had become pale, thin, and weak. The heart and lungs were in sound condition, and the menses were regular; but, on examination, a large mass was discovered in the right side of the abdomen. It extended from the right groin to near the edge of the ribs like a Bologna sausage, was doughy to the touch in greater part, but towards the top felt harder and more tender. She said that, for a long time, she had felt a fulness and stiffiness there in stooping, and also whilst lying straight out in bed; and further added, on finding me make particular examination, that she had a sister (who has since seen me) whose disease commenced with a swelling in the right side, which gradually extended over the the abdomen, and finally maturated to an abscess, which is now discharging in vast quantities from the groin, and carrying her rapidly to the grave. My conclusion was, that there wa some growth, or other cause of pressure in the neighbourhood of the liver; that this caused obstruction to the ascending colon, and that the mass of the present swelling consisted of long retained fæces, all the other symptoms being mere consequences of this state of things. She was ordered mild, softening, but not drastic, purgatives, and also injections, and took the liquor pepsiniæ in combination with soda and hydrocyanic acid. At the next visit she reported that the stomach felt easy, that she had not vomited since she saw me, and that there had been larger and more easy evacuations from the bowels. She could stoop and lie straight with more ease. Under a continuance of the same treatment the elongated mass disappeared, and then a roundish lump became distinctly perceptible under the edge of the liver, slightly tender to the touch. Not viewing it, from the appearance of the patient, as malignant, she continued the treatment, and applied tincture of iodine over the lump. It has now disappeared, so far as manipulation goes; but, though she feels very well, with no return of her old torments, still she is conscious that there is something in that quarter that burns and shoots with a curious pain after any hard exertion. The medicine under discussion could never have removed either the lump or even the fæces, per se; still it has proved a valuable subsidiary agent, if not essential.

CASE II. Mrs. B., the wife of a respectable farmer in Worcestershire, aged about 35 , first called at my house with a friend, in a nervous and excited state. She complained of indigestion, and what she said had been called chronic dysentery; for which she understood there was no cure. She said she could eat, but it did her more harm than good, giving her pain, constant eructation, and rattling of wind in the bowels, and often she vomited. Her bowels, she said, would be moved five or six times while dressing in the morning, and nothing would come but "slime and corruption," as she worded it. She had been in the habit of having chalk mixture, with laudanum, etc., which quieted the bovels for a time, but the symptoms always returned. The liveliness of her manner and eyes, her good complexion, and quiet pulse, made me doubt the existence of dysentery; but, under the impressions arising from the ac- 
count, I first prescribed mercury and opium, and doses of castor oil, with little effect; and in one of her severe attacks I was summoned into the country. I then found the stools slimy, and complaints of severe abdominal pain; but she looked lively, spoke briskly, and moved about the bed in any direction with ease. This, to my mind, was quite inconsistent with that depression of dysentery, which will soon bend down the strongest men. On examination, the tongue was rather furred, the epigastrium and right side tender to touch, and there were discoverable about the navel several internal lumps, one solid, the rest yielding to pressure, and resulting, under such pressure, in the rushing backwards and forwards of flatus. She said, "That is how it serves me; when it fixes, the pain is dreadful; and when it shifts I get easy; but it only shifts for a time to fix again." It appeared obvious that this flatus was imprisoned within the folds of the transverse colon, that pressure could move it backwards and downwards in the ascending colon, but that there was some impediment, be it a tumour, or fibrinous band, or impacted fæces, that prevented its orward passage towards the rectum. Thers was no tenderness over the lower part of the abdomen, but a great deal of dulness and incompressibility in the course of the descend ing colon. Under this diagnosis, I stopped all medicine by the mouth, excepting a pepsine mixture, and ordered a succession of injections, consisting of nothing but warm water with a little olive oil. Of the benefit to be derived from this she was at first a little sceptical, as she felt so convinced of having been long purged, and that nothing could be in her. However, on the visit of the following day, I found arranged in another room a series of vessels to the number of six, some nearly half full others with but little in them, graduated specimens of each successive discharge, and varying from the hardest and darkes scybala to black, pultaceous, clayey stool; and, lastly, what might be called thin dark bile. There was in this last a good deal of heavy earth-like settling, arising, apparently, from the quantities of chalk she had taken; and all was offensive in the extreme. She now felt convinced of plain facts, and expressed herself as being much better. Still there was the lumpiness about the navel, and the confinement of flatus, though it did not give the same pain. For some time she took alterative doses of hydrargyrum cum cretâ, and Dover's powder at night and liquor pepsiniæ with her food, while she persevered with the simple clysters till the evacuations should become of natural appearance. By that time she felt well; and though the latent cause of obstruction may still exist, yet, by keeping an open channel by the above safe and simple means, she eats and drinks, and goes about her usual avocations with comfort.

D. DYSPEYSIA FROM ULCERATION OF THE STOMACH, ETC.

CASE I. Mr. J. H., a schoolmaster, of Staffordshire, aged 38 , had been afflicted with severe dyspepsia for several years and, in spite of treatment by soda and bitters, etc., it had steadily gained upon him, till his whole constitution got greatly impaired under loss of nutrition. At the extremity of his illness, when I was consulted, he complained of agonising pain after almost every meal; his tongue was foul; the epigastrium very tender and retracted; the bowels costive; and if he did not vomit three times a day he never vomited less than once, the undigested matter coming back very sour, and sometimes consisting of pure coagulated blood, like coffee-grounds. The attacks of pain and vomiting invariably supervened after horse riding, walking up hill, or even speaking for a little time. $\mathrm{He}$ was also much emaciated, his cheeks very hollow, and the skin of a pale lemon colour, so that he was called "the walking ghost" by his neighbours. Though no tumour or hardness could be detected, all these symptoms quite convinced me at the time of the existence of a malignant hardening and ulceration. $\mathrm{He}$ was advised to cease from the toil of school duties, as he was not quite dependent thereon; to keep easy, and live upon spoon meats. He was also given colocynth pills for the bowels; and for the hamorrhagic ulceration quinine and nitrate of silver before food, while he took the alkalised liquor pepsiniæ, with morphia and hydrocyanic acid, after each meal. Under this treatment the symptoms were arrested, and he gradually improved in flesh, strength, and colour. The pains and vomitings subsided, he began to be able to bear stronger food and drinks, and he could walk and talk without the old discomfort. He has now regained his former bulk and florid complexion, and his appetite is sound. He is still aware that the stomach is his weak point ; so that if he eats beef, pastry, or the like, they pain him, and swell him up. The liquor pepsiniæ removes such symptoms, and he therefore takes it occasionally. From the happy result, I am now disposed to with- draw my former fears of malignant action (though for such fears there were sufficient grounds), and to view the case as one of simple ulceration. Death alone can reveal the whole truth ; but it seems very clear, from the whole history, that the peptic liquor was here the grand instrument of curation; for calumba, creasote, and all other ordinary settlers of the stomach were only wont to derange it the more. The patient himself has the most lively consciousness of the beneficial effects of the pepsine.

CASE II. Miss S. J., a girl of 18 or 20, was brought by her mother to me from Cheltenham, labouring under pain and fulness of the epigastrium and right side, vomiting of blood, and sometimes of purulent matter. She was excessively anæmic, her skin being nearly white, and the legs oedematous. There had been no catamenia for a considerable time, and her father, as re ported, had died of cancer of the stomach. She became worse after the journey. I saw herin bed, and detected a rounded swell. ing to the right of the epigastrium, which I inferred might be a hepatic abscess, complicated with stomach ulceration. At this time she lay faint and helpless, vomiting everything she ate, sometimes intermixed with blood, and occasionally being composed entirely of muco-purulent matter combined with bile. She was afraid to speak above a whisper, her tongue and mouth were parched, and her legs pitted deeply under pressure; the pulse was small, frequent, and thready, about 140 per minute. Soothing poultices were applied over the swelling, large masses of hard round fæcal matter were removed by injections, nitrate of silver was administered before food, and the alkalised liquor pepsinize, with hydrocyanic acid, was given after food, at intervals of one hour. At the same time the food was entirely pultaceous or liquid, and consisted of the smailest quantities at a time, seldom more than one teaspoonful. After several fluctuations, and occasional severe attacks of purulent vomiting, she gradually began to amend. So soon as the above symptoms abated, she went through a course of quinine and steel; and, after a tedious treatment of about ten months, she recovered plumpness, colour, and strength, contrary to the expectations of all her friends and acquaintances. The remedy could have little power over hepatic abscess; but I can scarcely see how, in her utterly reduced condition, she could have gone through the treatment without the support derived from the solvent action of the pepsine upon the food-oysters, arrowroot, and milk and wine, having all been previously rejected.

CASE IIr. Mrs. M. C., a married person, aged 28, pale and delicate, had had tenderness of the epigastrium and right side for many years; but recently the evil had become greatly aggravated, and she also suffered under an extensive bronchitis, chiefly implicating the right lung, with painful dyspnoea, and universal sibilant respiration. The pulse was 140 ; and, from the alarming condition of the chest, phthisis had been diagnosticated, and country air and cod-liver oil suggested as a last resource. From the general appearance, I was not equally disposed to believe in the presence of tubercle, but rather directed attention to the stomach and liver. There was retraction of the abdominal muscles, and pain and tenderness all over the right side, from the shoulder to below the umbilicus but in the epigastrium it was extreme, so that she shrank under the slightest pressure, and feared to take a common inspiration. Besides the vomiting, which was very acid, and th asthmatic bronchitis, there were immense discharges of lithates by the urine, with pain in the back, and a suffocating cough. She had to be propped up in bed, and supported under the least effort. Six leeches were applied over the stomach and along the right side at once; and these were followed up by a series of blisters, while she took antispasmodic diaphoretics, with small quantities of liquid food and pepsine largely im bued with soda, and had daily injections of decoction of poppy. Under this treatment, continued for some time, the asthmatic bronchitis gradually abated, the urine became clear, and the pain slowly departing from other parts, narrowed and narrowed to a lesser circle, until the seat thereof could be covered with a half-crown piece immediately under the point of the sternum; and she took quinine and nitrate of silver with marked benefit. She was now fast improving, so that I had ceased attendance, when an event occurred in the house which led to great bodily exertion and excitement on her part, and the eating of some beef and pickles to supper. Next morning I was requested to attend, and found all the stomach symptoms greatly aggravated. She suffered intense pain, and vomited everything she took. By and by she threw off muco-purulent matter in great quantity, intermixed, it seemed, with fæcal matter : meanwhile the bowels were confined and racked with spasm. As calomel and opium had always produced very bad effects before when. 
ever administered, she now had only injections of decoction of poppy, by the machine with long tube, and draughts of soda, morphia, and hydrocyanic acid; while blistering was renewed over the epigastrium, and nothing was allowed but a teaspoonful of gruel or milk at a time. By this means the excessive irritalility being overcome, she resorted afresh to the quinine and silver pills with constant and marked effect. These she took before food, and the liquor pepsiniæ, with morphia and hydrocyanic acid after, and so again gradually recovered. Nothing, however, but liquid food of the lightest nature was permitted; and she herself soon saw, that so soon as she partook of hard, solid, or otherwise indigestible food, so surely she had a relapse. This fact having made her cautious, she conformed strictly to rule, until she found she could eat almost anything with impunity. She has now gained her original flesh, colour, and strength ; though quite aware of a something at the pit of her stomach, which does not admit of being trifled with. Both sides of the chest have a clear resonance, the respiration is soft, 16 to 18 in the minute, and the pulse ranges from 65 to 80 -all clear proofs of the absence of pulmonary tubercle.

\section{E. Dyspepsia with maitgnant disease of stomach, liver,} ETC.

CaSe r. Mrs. M. B., an elderly widow, and housekeeper, consulted me in regard to long standing indigestion, with lancinating and burning pains in her right side. She was attenuated to the last degree, of shriveled lemon coloured aspect, sunken and knotty in the abdomen, and felt great tenderness on pressure of the stomach and liver; while, along the edge of the latter organ, a series of hard lumps could be felt The little she ate lay heavy, and the stools were pale. Frictions of mercury, and the exhibition of the ordinary stomachics had little availed; but on giving mercury and chalk with ox gall, and a liquor pepsiniæ mixture, the alteration was great. The stools improved, the pains were subdued, and she gained strength, and even a little more fulness and colour of the face. The organic disease remains, but its most troublesome symptoms are subdued.

CASE Ir. Mrs. S. R., carrying on the business of a master carrier, had been the victim of what she called $\mathrm{a}$ "horrible bad diges tion" for some years past. She feared to eat for the pain, had constant flatulence, vomited several times a day, and her bowels were always bound, and difficult to be moved. She had been stout, but had wasted to skin and bone, the skin being of a pale straw colour. As soon as she lay down the examination revealed the presence of a hard lumpy tumour between the navel and the breast bone, which $I$ inferred to be cancerous. Injections were ordered, and pepsine was administered, with morphia and hydrocyanic acid, after liquid or pultaceous food, while a belladonna plaster was applied; and her report is, that this is the only medicine that has ever subdued her bad symptoms without inducing something else unpleasant. She can now attend to her business.

Case IIr. Mrs. E. C., a widow, aged 54, with symptoms so similar to the above that they need not be described, had also a hard tumour in the same place. She has found, in the course of journeying from place to place, that she cannot obtain ease under any other treatment than the above. She there fore carries her bottle always about with her, and has gained in flesh, strength, and colour, in spite of the continued pre sence of her evil tumour. She now enjoys life by keeping at ease.

Case rv. Mrs. F. M. was, in almost all respects, similar to the above two: faint, emaciated, straw coloured, with pain and vomiting after food, and a tumour in the epigastrium. The treatment was about the same, and she feels easy.

CASE v. Mr. W. T., a broker, 48 years of age or so, had been long the victim of dyspepsia, and had undergone many a series of treatment with temporary ease, the disease still advancing. It did not appear that anything specific had been made out. He had the pains, and vomitings, and constipation, was thoroughly emaciated, and of a deep straw colour, inter. mixed with smokiness, as it were. He had the additional bad symptom of swelled legs; and, on examination, there was discovered a hard, stone-like mass to the right of the epigastrium. Purgatives were used, a belladonna plaster applied, and the alkalised liquor pepsiniæ, with morphia and hydrocyanic acid, given after liquid food; after a short period he also had quinine. So much easier did he feel from this, that he began to think himself cured, and acted as usual. In consequence I was again sent for, under feelings of much alarm. Having in dulged his fresh gained appetite, and neglected his bowels, the pain, the sickness, and swelling of the legs had returned, and he also feared that the tumour had suddenly grown to an immense magnitude. It was obvious, however, that it all arose from the hepatic tumour pressing on the colon, and causing it to be gorged with retained fæces. Repeated injections removed all the mass, except the originally discovered solid growth; but he never again rallied from the debility, swelled legs, etc., and so died. I was not present at the post mortem examination; but the existence of a malignant tumour was reported to me.

F. TUBERCULOSIs, AND TABES MESENTERICA OF INFANTS.

The number of these cases that have presented themselves precludes my entering upon thein individually. Let it suffice to picture them generally, and according to their broad features: to wit, the wrinkled, discontented, fretful faces of the young children, rather resembling those of old men and women in the most unhappy humour possible; the small shrunken chests; the large toad-like bellies; shriveled extremities; and bloodless wax-like fingers. Such patients often have voracious appetites, without any good results; the food passing off in diarrhœa, without having been digested. By means of hydrargyrum cum cretâ and Dover's powder, and the liquor pepsiniæ by itself after food, the changes in such children have been very extraordinary, especially when the diet has been consistent with the other treatment, and goats' or asses' milk used, along with raw egg. The same results will accompany its use amongst the pot-bellied young of the lower animals. My daughter has often been amused with its rapid effect upon a poor kitten in that condition, now grown to be a large, active, and healthy cat.

\section{G. DYSPEPSIA WITH EXTREME ALBUMINURIA.}

CASE I. Miss E. P., the daughter of a publican, about 20 years of age, had begun to decline in health for some years before. Her flesh and colour began to decrease about two years before seeing me; and she became weak, bronchitic, and short of breath, while her legs swelled, and the menses had disappeared for eighteen months. She had been treated for this anæmia and amenorrhœa, and had hoped that the re-establishment of the menstrual flux would put her quite right; but it never did appear. On examination she was found emaciated, with much whiteness of the cheeks, canthi, lips, tongue, and gums. Her chest was oppressed, her skin dry, her cheeks under the eyelids swelled, and her legs and thighs immensely œdematous, going into folds and sulci, almost resembling elephantiasis, yet pitting freely under pressure. She had pain in her back, rose frequently in the night time to make water, and the urine passed was almost entirely coagulable albumen. The case appeared very desperate; but, by ordering the recumbent position, and employing tonics, diaphoretics, and diuretics, along with bandages to the legs, the dropsical swellings and the cough gradually disappeared after a certain time; and then, under a good diet, and a free allowance of eggs and porter, accom. panied with quinine and iron, followed always by liquor pepsiniæ she rallied so far as strength, flesh, colour, sound sleep, and less frequent micturition could indicate. She also menstruated two or three times in the course of the treatment, and has felt for some time past so well as to attend to her father's business with ease. On a recent examination of the urine, the albumen was somewhat diminished, but still in great amount, fully three-fifths of the urine. She continues the eggs, with quinine and steel, and takes the liquor pepsiniæ whenever her meals lie heavy.

CAse II. J. B., an elderly man, with sallow puffy face, swelled legs, pain in back, and immense discharges of albumen and blood by the urine, had first the bleeding stopped by large doses of acetate of lead and opium, and afterwards the dropsy overcome by tonics and diuretics. Subsequently he used quinine and steel with his food, consisting much of eggs, and liquor pepsiniæ after it. The albumen remains much as before, but there is no blood. He feels easy, and does not go on from bad to worse as formerly. He sleeps well, eats well, and enjoys working in his garden.

\section{H. DIABETES.}

Case. W. W. Esq., a gentleman of our own profession, con sulted me between six and seven months ago, labouring under diabetes of eighteen months or two years' standing. He felt enfeebled; the skin was dry; he slept badly; the urine was in great quantity, and highly charged with sugar. He had been obliged to relinquish practice. As he is a professional man, and a man of talent, I shall allow him to report for bimself, by quoting from his letters. He began a course of liquor pepsinia, with quinine and steel in the beginning of July, and the fol- 
lowing are extracts from communications of successive later dates.

"July 16th, 1856. I am pleased to inform you that I am progressing very well. The liquor pepsiniæ quite agrees with me; especially in the form of mixture which you recommended, as I have a little acidity and flatulence. I do not make much, if any, more water than the usual quantity; certainly not so much as I have taken of fluids. Specific gravity about 1030 No particular thirst; skin acts properly; appetite good; I sleep well.'

"August 20th, 1856. I am pleased to inform you that I am much better, being considerably improved in strength. I have no symptom of indigestion, my stomach performing its func tions well at all times, and my appetite being good, withou being ravenous. The urine is $10 \% 8$, and about 60 ounces in 24 hours, and containing less sugar. Pulse 80 to 85 . Skin acts naturally, with the natural smell under armpits, etc. Indeed I am much stronger. I consider the mixed diet you allowed has, besides its greater agreeableness, done me good; and my stomach now can digest anything. My bowels are perfectly regular, and I sleep well. I have no pains in $\mathrm{my}$ head."

"Nov. 24th, 1856. I sleep well, and soundly, and walk from two to four or six miles every morning, according to weather; besides this, I ain engaged in helping a professional friend." (Here he describes his habits of diet, a mixed one, with porter, brandy-and-water, and light pale sherry.) "I have taken the liquor pepsiniæ, with the iron and quinine, three times daily; and lately only twice. My appetite is remarkably good; my bowels are regular, not the least costive. Though I feel so much better, I wish to go on with the pepsine, etc. Two days I was without it, and did not feel so well. The in crease of weight since taking your medicine was eleven pounds a fortnight agro, and I feel on the increase. I can eat any thing; pork pie or any meat to breakfast. I do not make more water than an ordinary person, certainly not so much as I drink. Specific gravity 1030 ; and yet, with the liquor potassæ test there does not seem to be any great amount of sugar. Though I do not wrap un at all, I do not feel the cold as I used to do. I feel deeply grateful to you. So well do I feel that I think of recommencing practice after Christmas. There is one symptom worthy of remark; and that is, that I feel better after a hearty meal, such as breakfast and dinner, both of which I eat heartily."

The foregoing are but a few specimens culled out of a great number. I make no further comments, as the facts speak for themselves to all rational physicians, and to my professional brethren in general; but I would merely add, as a standing caution, that the benefits of the remedy are not to be expected from its random or empirical use, but only when such use is grounded on a scientific review of all the important functions of the body in each individual case.

\section{ACETATE OF POTASH IN RHEUMATIC FEVER.}

By JoHn R. Nicholson, M.D., Redditch.

Frequentiy the remedy most successful in the treatment of disease in hospital is not the best adapted for use in private practice. In the latter case, a new set of conditions arise. For the necessary discipline of a well-ordered hospital ensures due attention being paid to ventilation, temperature, diet, nursing, and frequent observation of the patient, all greatly modifying, directly or indirectly, therapentic effects; but these conditions can only be partially, if at all, secured in the homes of the class which form the bulk of a general practice. Disappointment very often ensues, therefore, to the general practitioner in the use of remedies founded solely upon the dicta of heads of hospitals, and he becomes wary of risking his reputation on such.

Dr. Sandwith has given, in the Jounnal for February 7 th, the results of fourteen cases of rheumatic fever treated in hospital with acetate of potash. Twelve cases of this disease have come under my professional care in the preceding two years; of these, nine were treated with acetate of potash, and in all of them the remelly was completely successful in speedily eradicating this painful affection.

The ages of the patients varied; one was aged 11 ; two were under 20; four were aged from 21 ) to 30 ; one was 36 ; one above 40. Their conditions varied in as great degree, from the well-to-do farmer to his labourer; from the munufacturer to the mechanic; the youngest patient was the daughter of a needle manufacturer in comfortable circumstances; and her parents informed me that she had twice previously suffered. This was the only case in which any symptoms of heart disease made their appearance; and in her they rapidly yielded to treatment by calomel and leeching, acetate of potash being given at the same time.

The period of treatment varied in the different cases from ten to twenty-eight days, the average being fourteen days; and, excepting in the girl above mentioned, no leeching or blistering was required.

On one point Dr. Sandwith does not, I think, sufficiently insist. It is my practice always to commence the treatment by giving a pill of calomel and rhubarb, followed by the common black draught. By this means the diuretic action of the acetate of potash is determined more speedily and effectually, a mild diaphoresis being established at the same time. The formula for administration, though slightly differing from that of Dr. Sandwith in detail, is essentially the same. I prescribe the acetate of potash in doses of ten to fifteen grains in a mixture containing bicarbonate of potash and orange svrup, to be taken with lemon juice in the effervescing state. This forms an agreeable medicine to the patient, who is apt to complain of the saline taste of the acetate of potash given alone. I am satisfied, from frequent and mortifying failures in its administration, that these beneficial effects are not to be attributed to the lemon juice solely; but, given with the acetate of potash as above, it undoubtedly promotes and assists the action of that remedy.

The advantage in chronic rheumatism was not so marked as Dr. Sandwith obtained; yet when combined with the nitrate of potash and spirit of nitrous ether, acetate of potash undoubtedly exercised some influence over that disease, but not to the extent expected.

\section{P R OLA P S O O TH E U T R U S.}

By John Bassett, Esq., Birmingham.

[Read before the Birmingham and Midland Counties Branch, February 12th, 1857.]

I PROPOSE to relate to the Society to-night the particulars of four cases of prolapse of the womb, and subsequently to make some general remarks upon the causes and treatment of this displacement.

CASE I. A. H., single, aged 28, a housemaid, consulted me in April 1854, for a bearing down, which she stated had been troubling her for some months, and was gradually getting worse. She attributed it to frequent running up and down stairs. On examination, $I$ found the womb protruding through the os externum ; it presented a bright pink appearance, and was about the size and shape of a pear. There was no heat, abrasion, or discharge. Her general health was not particularly disordered, but she did not consider herself strong. Rest and an astringent injection were ordered: and in a few days a pessary was applied. This not proving sufficiently large, another was substituted. Complete relief followed, so that she was enabled to resume her occupation. I saw her on several occasions subsequently, and once or twice removed the instrument to clean it. At the end of two years she was so far recovered as to be able to dispense with the use of the instrument.

CASE Ir. Mrs. G. consulted me in August 1853, for a bearing down. Her history was that she was twenty-eight years of age; that she had been married four years, and was the mother of two children, the youngest of whom was three months old. She had never been a particularly strong woman, but since her last confinement had been quite unable to walk about. She suffered from a bearing down after her first confinement, but not to a serious extent. When she consulted me, she com. plained of lumbar and hypogastric pains, with sa much weight and bearing down, as entirely to prevent her from walking. She had a furred tongue, impaired appetite, increased heat of skin, an accelerated pulse, scanty, high-coloured urine, and a costive state of the bowels. On examination, I found the vagina hot and swollen, the uterus enlarged and low down, and the passage moistened with a copious mucous discharge: a large fissure existed in the perinæum, which resulted from laceration in her first confinement. The examination did not give much pain. I prescribed rest in the recumbent posture, a lead and poppy injection, a saline aperient mixture, and a fa- 